\title{
Expediency of application of explosion-relief constructions to ensure explosion resistance of production buildings
}

\author{
Anton Lyapin ${ }^{1 *}$, Anton Korolchenko ${ }^{1}$ and Evgeniy Meshalkin ${ }^{2}$ \\ ${ }^{1}$ Moscow State University of Civil Engineering, 129337, Moscow, Yaroslavskoye shosse, 26, Russia \\ ${ }^{2}$ NPO PULS, 107014, Moscow, Rusakovskaya street, 28, Russia
}

\begin{abstract}
The article presents a model of economic evaluation and selection of explosion-relief constructions (ERC), as well as determination of explosion protection efficiency of buildings and structures provided on a stage of construction. It has been shown that definition of economic efficiency of ERC is the evaluation of its application for buildings with remote or automatically controlled production. It has been determined that an important role in design of explosive industrial facilities is played by selection of the economically feasible and effective materials for ERC. When selecting materials it is necessary to consider probability and yield of explosions. Necessity to create the methods allow considering such probability has been revealed.
\end{abstract}

Amount of damages caused to the company as a result of explosion of combustible gases, vapors and dusts inside the building with explosive production depends on the effectiveness of explosion safety measures $[1,2]$.

The results of inspection of emergency explosion consequences and calculation of explosion loadings for separate buildings, which external protection was designed taking into account the installation of explosion-relief constructions (ERC), have shown that the main protecting and bearing structures of affected buildings and, sometimes, adjacent buildings can be damaged together with destruction of ERC [3].

The measures proposed to ensure explosion protection of industrial facilities differ from existing differentiated approach to choice of types and number of ERC for each specific case [4-9]. Besides, manufacture of ERC, except the specially designed covering elements, does not require additional expenses because the offered constructions are standard and produced on an industrial scale. Application of ERC in the cladding of buildings could limit the damaged area by sizes of destroyed construction. Such destructions minimize the amount of damage due to the absence of additional costs for restoration of the process equipment and the main building structures [10-13]. This can sharply reduce the costs for rescue and recovery operations and decrease the losses from temporary termination of the productive activity.

It should be noted that implementation of explosion safety measures for industrial facilities, which technological processes connected with generation of combustible gases,

\footnotetext{
*Corresponding author: lyapin@mgsu.ru
} 
vapors and dust, could require additional costs. Methods of passive redundancy, such as strengthening of the main bearing structures, increase of their rigidity, change of the building constructive scheme, etc., could also be used to improve explosion safety of buildings [14-20].

Extension of ERC's area as well as increase of bearing capacity of the main structures has improved explosion safety of building. However, initial cost and maintenance costs of ERC have increased as the mounting cost of $1 \mathrm{~m}^{2}$ of ERC and of main cladding constructions are varied considerably. Allowances for depreciation and construction maintenance have also increased. Moreover, heat losses trough ERV have entailed additional maintenance costs.

The problem of implementation of explosion safety measures should be considered separately for each industrial facility.

It is obvious that industrial facility with production controlled by operated personnel should provide explosion safety measures in order to protect the people, the process equipment and the main bearing structures.

While, for industrial facilities with automatically and remote controlled production, where the probability of emergence explosion is rather small, destruction of the building structures will be economically justified; but only if the restoration costs will not exceed the installation costs of ERC.

To determine the economic feasibility of proposed type of ERV we should solve one of the following tasks:

1) To define the economically justified structural concepts, materials and required area of

ERC (in case of presence of operated personnel);

2) To evaluate the feasibility of ERC application taking into account analysis of its mounting costs and the total costs of construction, maintenance and restoration of industrial facility (in case of absence of operated personnel).

Thus, definition of economic efficiency of ERC has been restricted by assessment of its application for buildings with remote or automatically controlled production. In this case it should be determined whether the application of ERC is necessary. If it is necessary we should find the optimal type, which will provide appropriate explosion safety.

When designing explosive production it is important to find the cost-effective materials for ERC manufacturing, and also to minimize total costs of construction and maintenance of building in case of ERC installation. To calculate the sum of costs occurring at different times we have to convert them to equivalent costs at a base time using the compound interest formula (in accordance with «Instructions for definition of economic efficiency of capital investments in construction» (SN 423-71)):

$$
B=1 /\left(1+E_{d r}\right)^{t}
$$

Where $E_{\mathrm{d} . \mathrm{r}}$ - discount rate used to convert costs occurring at different times to equivalent costs; $E_{\mathrm{d} . \mathrm{r}}=0,08 ; t$ - reduction time period, years.

When we choose materials for ERC we should also consider the frequency of emergence explosions. But the current guidance and regulatory literature on economic evaluation of design decisions, using stochastic and probabilistic rates, does not contain certain recommendations. To develop the methods, considering probability of explosions and degree of ERC destruction, we should have statistical data on frequency of explosions at the similar industrial facilities. Such statistical data, have been obtained from industrial facilities (connected with production of butadiene, cumen hydroperoxide, ammonia, etc.), and the probabilistic and statistical methods allow calculating the average time $t_{\mathrm{av}}$ between explosions:

$$
t_{\mathrm{av}}=1 / \lambda_{\mathrm{s}}
$$


Where $\lambda_{\mathrm{s}}-$ damage rate of structures, measured by amount of damages during one year of operation;

$$
\lambda_{\mathrm{\kappa}}=\frac{n \lambda}{N r(t)}
$$

$n$ - total number of a single-type building structures;

$\lambda$ - frequency of explosions;

$N$ - number of a single-type building structures under observation;

$$
N=(r-1) /(N t r)
$$

$r(t)$ - number of explosions during period of observation.

Materials for ERC can be selected according to criterion of minimal total costs $P$ (thousand of Russian rubles, further "thou. rub." ) for fabrication (mounting), restoration and maintenance of structures during the operation period of industrial facility:

$$
P=C_{\text {ко }}+\sum_{i=t_{s r}}^{r(t) t_{s r}} C_{i}-\frac{C_{k d}}{\left(1+E_{k o}\right)^{i}}+\frac{E^{\text {year }}}{E_{k d}}
$$

Where: $C_{\text {ко }}$ - initial estimated cost of ERC, thou. rub.;

$t_{\mathrm{av}}$ - average failure-free operation time, e.g. time between explosions (calculated by formula (2), hours;

$C_{i}$ - direct costs of ERV restoration, thou. rub.;

$C_{\mathrm{kd}}$ - depreciated cost of destroyed structures, thou. rub.;

$i$ time periods of explosions, years; $i=t_{\mathrm{av}}, 2 t_{\mathrm{av}}, \ldots, a t_{\mathrm{av}}$;

$a$ - value, which indicates the whole number of building restorations (consider only integer part of ratio);

$$
a=\left(T_{s l}-1\right) / t_{a v}
$$

$T_{\mathrm{sl}}$ - standard service life of building, years;

$E^{\text {year }}$ - total annual operating costs, allowances for depreciation and maintenance of structures, thou. rub.

The last item of equation (5) accounts total operating costs for the entire period of operation. As the total annual operating costs $E^{\text {year }}$ occurring at different times, so we have converted them to equivalent costs at a base time. The first and the second items of equation (5) account investments of initial application period of ERC; therefore we have accepted initial operation time of ERC to determine the operating costs.

Operating costs can be converted by following formula:

$$
E^{\text {year }} T_{s l}=\sum_{i=1}^{T_{s l}} E_{i}^{\text {year }} \frac{1}{\left(1+E_{d r}\right)^{i}}
$$

If operating costs have not been changed for years, e. g., $E_{1}^{\text {year }}=E_{2}^{\text {year }}=E_{3}^{\text {year }}=$ const, $E^{\text {year }}$ value can be taken outside the summation symbol. So the remaining part of expression have been presented as the sum of decreasing geometric progression with the first member $a$ and the denominator $g$ equal to $1 /\left(1+E_{\mathrm{dr}}\right)$, (if $\left.T_{\mathrm{sl}} \rightarrow \infty\right)$.

$$
\sum=a /(1-g)=1 / E_{d r}
$$

In this case total operating costs are equal to

$$
\frac{1}{E_{d r}}=E^{\text {year }}
$$


Protection from explosions of flammable liquids can be provided by:

- Application of ERC;

- Strengthening of bearing structures;

- Combination of ERC application and strengthening of bearing structures.

Thus we have been faced with the choice of such protective measures, which require minimal investment and provide the specified degree of explosion safety.

The minimum total cost has been determined by following formula:

$$
P=C_{s}+C^{e s t} E_{s} F_{p r} t+\frac{1}{E_{d r}\left(1,06 C_{i}\left(a_{1}+\frac{\left.a_{2}\right)}{100}\right)+Z^{h}\right)}+\sum\left(Z_{i}+E_{s} F_{p r} t^{s u s p} /\left(1+E_{d r}\right.\right.
$$

Where: $C_{\mathrm{s}}$ - estimated cost of works on strengthening the main bearing structures, thou.rub.;

$C^{\text {est }}$ - estimated cost of explosion relief constructions, thou. rub.;

$E_{\mathrm{s}}$ - standard index of capital investment efficiency (index of profitability);

$F_{\text {pr. }}$ - estimated cost of production funds of the company (-ies), providing mounting of ERC, thou. rub.;

$T_{\mathrm{m} .}$ - mounting period, years;

$C_{i}$ - estimated cost of structures, thou. rub..;

$a_{1}, a_{2}$ - standard renovation deductions and deductions for maintenance of structures (from their estimated cost);

$Z^{\text {h }}$ - annual heating costs, thou. rub.;

$Z_{i}-$ costs of liquidation of explosion consequences in $i$-year, thou. rub.;

$\mathrm{t}^{\text {susp }}$ - suspension period of production connected with liquidation of explosion consequences, years.

The cost of strengthening of bearing structures $C_{\mathrm{s}}$ should be calculated for certain building. If $C_{\mathrm{s}}=0$, then specified degree of explosion safety can be provided only by application of ERC.

Estimated cost of explosion relief constructions have been determined according to the estimated prices on materials, products and constructions taking into account overhead costs. Economic effect $E_{i}$ of reduction in labor intensity and decrease in time of ERC mounting have also been considered:

$$
C^{\mathrm{est}}=C_{i}-E_{i} .
$$

Value of economic effect $E_{i}$ has been determined taking into account the value of labor intensity.

1. The labor intensity $m_{i}$ (person-days) have been calculated for every type of explosionrelief constructions.

2. The type required highest labor intensity has been accepted as initial.

3. Types required lower labor intensity, under equal production conditions (manpower resources, number of working shifts), have been given the economic benefit in relation to initial type.

For initial type $E_{i}$ value is equal to 0 . For other types $E_{i}$ value is a sum of tree values:

$$
E_{i}=E_{i}^{1}+E_{i}^{2}+E_{i}^{3}
$$

Where $E_{i}^{1}+E_{i}^{2}+E_{i}^{3}$ - economic effects of reduction of the semi-variable part of overhead costs and the part of overhead costs related to labor intensity and basic wage rate. 
Effect of reduction of the semi-variable part of overhead costs has been calculated by formula

$$
E_{i}^{1}=0,5 C \frac{K_{o c}}{\left(1+K_{o c}\right) 1.06}\left(1-\frac{m_{i}}{m_{\text {init }}}\right)
$$

Where: 0.5 - ratio of semi-variable part in the total amount of overhead costs;

$C$ - estimated cost of construction products, thou. rub.;

$K_{\text {oc }}$ - ratio of overhead costs; $K_{\text {н.p }}=0.12 \div 0.19$;

1.06 - ratio of planned accumulations;

$m_{\text {init }}$ - labor intensity by initial type, person-days

Effect of reduction of overhead costs, related to labor intensity has been calculated by following formula

$$
E^{2}=0.6\left(m_{\text {init }}-m_{i}\right)
$$

Reduction of overhead costs related to basic wage have been calculated by following formula:

$$
E_{i}^{3}=0.15\left(Z_{\text {init }}-Z_{i}\right)
$$

Where: $Z_{\text {init }}, Z_{i}$ - basic wage (by initial type and $i$ - type accordingly), rub.

The annual heating costs $Z^{\mathrm{h}}$ has been calculated by formula

$$
E^{h}=F_{p k} E_{m^{2}}^{h}=F_{p k} U_{h}\left(t_{i n}^{0}-t_{a v}^{0}\right) 24 \frac{T_{h}}{R_{o t} 10^{6}}
$$

Where: $F_{\mathrm{ERC}}$ - area of ERC, $\mathrm{m}^{2}$;

$E_{m^{2}}^{h}$ - heating costs, $1 \mathrm{~m}^{2} /$ year;

$U_{\mathrm{h}}$ - cost of 1 Mcal of heat, rub.;

$t_{\text {in }}^{0}$ - specified temperature of indoor air, ${ }^{\circ} \mathrm{C}$;

$t_{a v}^{0}$ - average temperature of outdoor air during heating period, ${ }^{\circ} \mathrm{C}$;

24 - hours in the day;

$T_{\mathrm{h}}$ - duration of the heating period, days;

$R_{\mathrm{ot}}$ - thermal resistance of wall or wall coating, $\mathrm{m}^{2} \cdot{ }^{\circ} \mathrm{C} \cdot \mathrm{h} \cdot \mathrm{kcal}$.

Costs related directly to liquidation of explosion consequences $(C)$ have been determined as follows:

1. If the area of explosion relief constructions allows preventing complete destruction of the building, then $C$ value can be calculated by formula

$$
C=C_{\mathrm{ERC}}+C_{\mathrm{ms}}+C_{\mathrm{p} . \mathrm{e}}+C_{\mathrm{adj}}+C_{\mathrm{cl} .}-D
$$

Where: $C_{\mathrm{ERC}}-$ costs of restoration of ERC; determined by estimate standards taking into account design costs;

$C_{\mathrm{m} . \mathrm{s}}-$ costs of restoration of the main structures (if explosion relief constructions are not able to reduce explosive load);

$C_{\text {p.e }}-$ costs of restoration of process equipment, pipelines and networks;

$C_{\text {adj. }}-$ costs of restoration of adjacent buildings and facilities;

$C_{\mathrm{cl}}$ - - costs related to cleaning of the territory from destroyed structures; actual cost of dismantling and transportation;

$\mathrm{D}$ - depreciated cost of damaged structures (can be accepted as $10 \%$ from initial cost of ERC).

Values of $C_{\mathrm{m} . \mathrm{s}}, C_{\mathrm{p} . \mathrm{e}}$ and $C_{\text {adj }}$ have been determined by multiplying the volume of restoration works by the relevant estimate norms. The necessary volume of restoration can 
be determined as average value according to statistical data.

2. If design of explosion relief constructions allows complete destruction of a building, then the costs related to liquidation of explosion consequences could be calculated by formula

$$
C=C_{1}+C_{\text {adj }}+C_{\text {cl. }}-D
$$

Where $C_{1}$ - costs of restoration of destroyed building, thou. rub.

For aggregate calculations $C$ value can be equal to cost of initial mounting of ERC. If the cost of structures have been changed in time then calculation should contain appropriate correction factor $K_{t}$.

$$
C=1,06 C_{i} K_{t}
$$

\section{Conclusions}

In accordance with considered model of economic evaluation and feasibility of ERC selection, as well as determination of economic efficiency of explosion protection of buildings and constructions, the following conclusions can be drawn.

1. Protection of buildings against effects of explosions, occurred inside production premises, is connected with additional costs for ERC. Therefore the very important task is to ensure explosion safety with the lowest total construction and maintenance costs of production building.

2. The value of average failure-free operation time is the fundamental parameter for economic evaluation of the selected ERC application expressed by destruction intensity which, as is known, is a random value. For its determination one can use the probabilistic and statistical methods.

3. When selecting materials for ERC fabrication it is necessary to minimize full installation and maintenance costs taking into account probability of emergency explosions. The method presented in this article allows minimizing such costs.

4. The equation (9) used to calculate the economic feasibility of ERC enables to define total costs of construction, operation and restoration of production building considering the probability of explosion. Analysis of this equation as well as further calculations shows that decrease of ERC area is economically justified for remote or automatically controlled industrial facilities, where explosions occur at intervals of 12-15 or more years.

5. The economic benefit of ERC calculated by described method is equal to $3 \%$ of total construction and maintenance costs for compressor buildings transporting combustible gases. The economic benefit of this method applying for such facilities will amount to more than 5 million rubles per year. As the list of explosive productions of chemical, petrochemical, oil processing and gas industries includes several dozen items, then economic benefit will amount to several tens of millions of rubles.

6. In order to optimize the building explosion safety coasts it is necessary to use the probabilistic methods which determine the risk of explosion depending on various protective measures. Meanwhile, the both the direct damage caused by explosion and the indirect damage connected with liquidation of a certain type of production and recovery of incapacitated powers should be accounted.

\section{References}

1. M. V. Beschastnov, V. M. Sokolov, M. I. Kats,Moscow, Khimiya Publ., 367 (1976)

2. Scientific and technical report, VNIITBKhP Publ., 22 (1978)

3. G. G. Orlov, A. Ye Leybman, A. I.Manasyan,Moscow State University of Civil 
Engineering Publ., 1 (1978)

4. I. O. Moen, M. Donato, R. Knystautas, J. H., Combustion and Flame, 39 (1980)

5. C. J. M. Wingerden, J. P. Zeeuwen, Journal of Hazardous Materials, 8 (1983)

6. A. F. Sharovarnikov, D. A. Korolchenko,Applied Mechanics and Materials, 475-476 (2013)

7. V. I. Gorshkov, D. A. Korolchenko, Yu. N. Shebeko, V. Yu. Navtsenya, A. K. Kostyukhin, All-Russian Research Institute for Fire Protection Publ., 800-808 (1997)

8. D.A. Korolchenko, A.F. Sharovarnikov, A.V. Byakov, Advanced Materials Research, 1073-1076 (2015)

9. D.A. Korolchenko, A.F. Sharovarnikov, Advanced Materials Research, 1070-1072 (2015)

10. D. Korolchenko, A. Tusnin, S. Trushina, A. Korolchenko, International Journal of Applied Engineering Research, 10 (2015)

11. L. P. Pilyugin, Pozhnauka Publ., 379 (2010)

12. D. A. Korolchenko, A. F. Sharovarnikov, Fire and Explosion Safety, 23 (2014)

13. D. A. Korolchenko, A. F. Sharovarnikov, Fire and Explosion Safety, 24 (2014)

14. S. M. Frolov, Combustion, Explosion, and Shock Waves, 48 (2012)

15. S. M. Frolov, Torus Press Publ., 6 (2013)

16. G. G. Orlov, D. A. Korolchenko, A. Ya. Korolchenko, Fire and Explosion Safety, 24 (2015)

17. D. A. Cherepanov, A. S. Ermakov, Fire and Explosion Safety, 25 (2016)

18. A. S. Ermakov, D. A. Cherepanov, Fire and Explosion Safety, 26 (2016)

19. O.S. Zosimova, Collection of materials of the XIX International Interuniversity scientific and practical conference of students, undergraduates, graduate students and young scientists, 473-476 (2016)

20. V.V. Holschevnikov, D.A. Samoshin, I.R. Belosohov, R.N. Istratov, I.S. Kudrin, A.P. Parfionenko, Fire-boom-bada-boom-safety, 3 (2011) 